\title{
O PEDAGOGO EMPRESARIAL COMO MEDIADOR DA GESTÃO DE PESSOAS PARA O DESENVOLVIMENTO PROFISSIONAL
}

\author{
Márcia Soares da Silva ${ }^{1}$
}

\begin{abstract}
RESUMO: Em pleno processo de transformação e informação, as organizações enfrentam um desafio considerável no desenvolvimento de suas equipes, e com tantas mudanças e competitividade torna-se muito importante uma estrutura organizacional que busque meios para o conhecimento, a preparação e a qualificação dos funcionários de acordo com o perfil desejado pela empresa. Partindo dessas premissas, o presente trabalho foi elaborado com o objetivo de compreender a importância da Pedagogia Empresarial; investigar o perfil e a atuação do Pedagogo na organização; e, compreender a necessidade e importância da gestão de pessoas para o desenvolvimento profissional. A partir daí, a metodologia adotada foi a de pesquisa bibliográfica e exploratória com coleta de dados e informações em diferentes fontes para obtenção de conhecimentos, assim, foi realizada leitura crítica e reflexiva para contextualizar e desenvolver o trabalho. Dessa maneira, as empresas necessitam dos serviços deste profissional para incentivar propostas de desenvolvimento humano, provocando processos de aprendizagens contínuos, alcançando assim um melhor aprimoramento, qualificação e desenvolvimento profissional.
\end{abstract}

Palavras-chave: Pedagogo; Organização; Desenvolvimento.

\section{BUSINESS EDUCATION AS A MEDIATOR OF PEOPLE MANAGEMENT FOR PROFESSIONAL DEVELOPMENT}

\begin{abstract}
In the process of transformation and information, organizations face a considerable challenge in the development of their teams, and with so many changes and competitiveness, an organizational structure that seeks means for the knowledge, preparation and qualification of employees according to them becomes very important. with the profile desired by the company. Based on these premises, the present work was elaborated in order to understand the importance of Business Pedagogy; investigate the profile and performance of the Pedagogue in the organization; and understand the need and importance of people management for professional development. From then on, the methodology adopted was that of bibliographic and exploratory research with data and information collection from different sources to obtain knowledge, thus, a critical and reflective reading was performed to contextualize and develop the work. Thus, companies need the services of this professional to encourage human development
\end{abstract}

\footnotetext{
${ }^{1}$ Márcia Soares da Silva: Formada em Pedagogia pela Faculdade Dom Bosco de Ubiratã. Pós Graduada em Educação Especial pelo Instituto São Francisco de Assis - ISFACES. Pedagogia Empresarial e Educação Corporativa do Centro Universitário Internacional UNINTER. MBA em Gestão de Pessoas do Centro Universitário Unicesumar. Mestranda em Ciências Sociais pelo PGC -Universidade Estadual de Maringá - UEM. marciamga019@gmail.com
}

Programas de Pós-Graduação em Ciências Sociais e Filosofia - UNIOESTE - Rua da Faculdade 645. Toledo - PR. CEP 85.903-000 Email: revistaalamedas@gmail.com 
proposals, triggering continuous learning processes, thus achieving better improvement, qualification and professional development.

Keywords: Pedagogue; Organization; Development.

\section{INTRODUÇÃO}

O presente trabalho é resultado de análises e reflexões baseadas em pesquisas e estudos que demonstram que, um dos grandes desafios enfrentados pelas organizações é a gestão de pessoa. Partindo dessas premissas, os objetivos norteadores desta pesquisa foram: compreender a importância da Pedagogia Empresarial; investigar o perfil e a atuação do Pedagogo na organização; e, compreender a necessidade e importância da Gestão de Pessoas para o desenvolvimento profissional. Com isso, foi possível adquirir uma aprendizagem significativa mediante as perspectivas do cenário empresarial, que por sua vez impõe aos seres humanos cada vez mais exigências.

Nesse contexto, a problematização direcionou-se à compreensão sobre qual o perfil e como deve ser a atuação do pedagogo como mediador da gestão de pessoas no contexto empresarial, tendo em vista que, atualmente, o mercado de trabalho exige profissionais qualificados e capacitados a atuar com objetividade e humanização, considerando a complexidade existente no contexto do relacionamento humano.

Considerando os estudos e pesquisas nessa área, a importância desse trabalho justifica-se devido à necessidade de compreender que, Pedagogia e Empresa formam uma parceria necessária porque buscam provocar mudanças no comportamento das pessoas. Além disso, com as rápidas transformações no mercado de trabalho as competências e habilidades do profissional Pedagogo têm sido cada vez mais valorizadas no contexto corporativo, uma vez que ele contribui para o desenvolvimento pessoal, profissional e humano dos indivíduos.

Com estas implicações, o grande desafio que se coloca para as organizações é a inserção do profissional Pedagogo Empresarial em seu contexto, o qual pode apoiar o entendimento dessas questões. Assim sendo, este profissional pode ser considerado o mediador na Gestão de Pessoas para o desenvolvimento profissional, que oferece novos caminhos e paradigmas para transformar, modificar e elevar o ser humano em sua totalidade. 
Para isso, o Pedagogo Empresarial deverá domínio de técnicas e práticas aliadas ao conhecimento, que somadas às experiências de profissionais de outras áreas, constituem importantes instrumentos para atuação na intervenção da Gestão de Pessoas.

\section{PEDAGOGIA EMPRESARIAL}

A princípio, é relevante compreender segundo Ghiraldelli Júnior (2006, p.20) que, "[...] a Pedagogia [...] diz respeito, em geral, à teoria da educação", é a área do conhecimento que se completa do estudo sistêmico do ato educativo.

O Pedagogo exercia suas atividades basicamente em espaço escolar, com as transformações ocorridas no meio organização, percebeu-se na necessidade de um profissional que pudesse mediar e aliar informações, experiências e conhecimento, para que o colaborador possa acompanhar e compreender todo processo de mudança dentro da organização e a sua volta.

\footnotetext{
A Pedagogia estuda e aplica doutrinas e princípios para um programa de ação, com os meios mais eficientes de formação, aperfeiçoamento e estímulo das faculdades da personalidade humana, de acordo com ideais e objetivos adequados a uma determinada concepção de vida (HOLTZ, 2006, p.28).
}

Desta forma, nasce no cenário empresarial um campo onde fica estabelecida a importância de um olhar crítico e reflexivo para que se possa provocar o conhecimento e o desenvolvimento das pessoas.

Duarte e Cabral (2010, p.92) compreendem a pedagogia "como a ciência cujo objetivo é a reflexão, ordenação, sistematização e a crítica do processo educativo".

Segundo Holtz (2006), a Pedagogia é a Ciência, desta forma acredita-se que o pedagogo dentro desse novo horizonte em que está inserido deverá utilizar-se de outras áreas como a administrativa, psicológica e filosófica para ter acesso a conhecimentos fundamentais na gestão de pessoas no espaço organizacional.

Já quando o assunto é Pedagogia Empresarial, Almeida (2006) ressalta que, é importante pensar em aumento da eficácia e eficiência por parte dos colaboradores como melhor maneira de conduzi-los a se desenvolver e a potencializar suas competências e habilidades. Pois, é investindo no desenvolvimento dos colaboradores 
que a empresa alcançará maior competitividade abrangendo o ponto de equilíbrio desejado por todos.

\begin{abstract}
Os eventos que se desenrolaram no Brasil e no mundo nos últimos 25 anos causaram profundas mudanças ao processo de reestruturação produtiva que levaram as instituições de ensino, cientistas, pesquisadores e organizações voltar sua atenção para a necessidade de desenvolvimento das pessoas no contexto empresarial (ALMEIDA, 2006, p.05).
\end{abstract}

Desta forma, o pedagogo trabalha a gestão de pessoas de forma a alicerçar e despertar no colaborador o desejo de um autoconhecimento e desenvolvimento e que possa ser construído diuturnamente por todos os envolvidos nesse processo.

Diante disso, Fernandes (2004, p.252) complementa que, “o mundo moderno em que vivemos hoje, impõe sobre os seres humanos, muitas exigências", isso acontece "para que os resultados sejam previstos almejando a eficácia das ações [...]". Nesse contexto, exige-se dos profissionais o máximo de conhecimento sobre o sistema gerencial, sobre a condução de pessoas e a obtenção de resultados. E, com isso, o ser humano passa a ser considerado como elemento que favorece a empresa na obtenção de resultados, assegurando um diferencial competitivo para a organização.

Mediante estas implicações, Almeida (2006) afirma que, há um grande desafio, ou seja, o Pedagogo é o profissional que deve apoiar o entendimento dessas questões no contexto corporativo, pois, o que sucede dentro de uma empresa é a necessidade permanente por novos saberes.

\begin{abstract}
A Pedagogia no âmbito empresarial se consome basicamente com os conhecimentos, as habilidades, as competências e as atitudes tidas como necessárias à melhoria da produtividade. Confirmando esse olhar de Pedagogia Empresarial, Almeida (2006, p.06) afirma que o foco desta é 'qualificar pedagogos e administradores para atuarem no âmbito empresarial, visando aos processos de planejamento, capacitação, treinamento, atuação e desenvolvimento do corpo funcional da empresa' (PAZ, CARVALHO, 2010, p.01).
\end{abstract}

Por isso, é possível afirmar na visão de Paz e Carvalho (2010) que, a Pedagogia faz conexão de forma perspicaz e dinâmica à empresa, tendo em vista que ambas agem em rumo à concretização de ideias e objetivos específicos, no esforço de provocar mudanças no comportamento das pessoas, sendo que, neste processo há aprendizagem, 
e esta por sua vez, é a especialidade do profissional Pedagogo. Nesse sentido, a Pedagogia Empresarial existe para apoiar a estruturação das mudanças, bem como a ampliação e aquisição de conhecimentos no ambiente organizacional.

\title{
O PERFIL E A ATUAÇÃO DO PEDAGOGO EMPRESARIAL
}

Na teoria de Machado (2011), o pedagogo empresarial deve ser o mediador no qual apresenta novos caminhos e desenvolve propostas educativas e de orientação para transformar, modificar e elevar o ser humano em sua totalidade. Desse modo, este profissional deve ser criativo, qualificado e sensível para lidar com os desafios cotidianos em sua atuação dentro da empresa.

\begin{abstract}
Ensinar é acima de tudo, relacionamento humano sincero e emotivo, com o objetivo de fazer manifestar mudanças positivas e definitivas nas pessoas. Ensino é o processo de se conseguir aprendizagem. Aprendizagem é mudança duradoura de comportamento, como resultado do que foi ensinado. Na empresa, as mudanças de comportamento devem acontecer, sempre com o objetivo de melhorar a produtividade pessoal e consequentemente a empresarial (HOLTZ, 2006, p.59-60).
\end{abstract}

Paz e Carvalho (2010, p.01) esclarecem em seus estudos que, “o pedagogo [...] tem o papel de conduzir o comportamento das pessoas em direção aos objetivos da educação, o processo de formação da personalidade humana equilibrada". Nesse contexto, dentre as responsabilidades do Pedagogo Empresarial destacam-se para seu perfil:

a) Experimentar e localizar recursos práticos para otimizar o rendimento profissional;

b) Conhecer intensamente e empenhar-se de acordo com os objetivos da organização;

c) Dirigir treinamentos para os funcionários e administradores que trabalham na organização, com direção aos objetivos humanos, considerando os já determinados pela empresa;

d) Realizar treinamentos, reuniões, eventos, festividades, exposições, enfim, atividades práticas indispensáveis ao desenvolvimento global dos colaboradores, 
motivando-os de maneira positiva, com a finalidade de aprimorar a produtividade e/ou desenvolvimento tanto pessoal quanto profissional;

e) Indicar de maneira conexa, os procedimentos mais efetivos das chefias para com os colaboradores e destes para com as chefias, com o objetivo de melhorar o aumento da produtividade da organização;

f) Favorecer um bom relacionamento entre os integrantes da organização, por meio de ações pedagógicas, garantindo consenso, harmonia e, logo, instigando a produtividade/rendimento.

Para Marques (2012, p.48) o perfil do profissional pedagogo "para hoje e no futuro é: ser organizado; ter conhecimento e empatia; ser treinado e comunicativo; e, ter boa aparência". Esses são pontos cruciais para que o profissional desenvolva seu trabalho com valor e qualidade na empresa.

O desafio desse novo profissional, diferentemente do que podem pensar alguns, não se resume a conduzir dinâmicas de grupo e preparar material de treinamento [...]. Isto requer muito trabalho [...]. É preciso estudos e observações cuidadosas do que está acontecendo dentro da empresa e entender o seu ecossistema, como ele funciona e por que existe um desequilíbrio dentro dele (ALMEIDA, 2006, p.03).

Para Lopes (2006) apud Paz e Carvalho (2010, p.01), o pedagogo empresarial ainda "promove a reconstrução de conceitos básicos, como criatividade, espírito de equipe e autonomia emocional e cognitiva".

E, Almeida (2006) complementa que, o perfil do Pedagogo Empresarial requer "perspicácia, observação, envolvimento, desprendimento, coragem, preparo técnico, ousadia, vontade, criatividade e desejo efetivo pela descoberta dos pontos de desequilíbrio" dentro da organização. Além disso, o Pedagogo na empresa também precisa dispor de humildade para a busca de opiniões, pois, recorrer à ajuda externa é de fundamental importância para enfrentar os desafios nessa área.

Diante dessas premissas, Fernandes (2004) enfatiza que, o pedagogo na empresa deve ser notado como o profissional que se encontra absolutamente agregado ao desempenho produtivo dos colaboradores da organização, tendo como encargo maior, desenvolver as capacidades, habilidades e competências dos todos os envolvidos. Para tanto, é indispensável uma parceria entre colaboradores e empresa para um resultado 
efetivo na melhoria e no aprimoramento de tudo o que fazem e/ou produzem, e nesse processo, a comunicação, o diálogo e o relacionamento é de suma importância para o crescimento e desenvolvimento como um todo.

[...] o pedagogo empresarial representa um fator importante no trabalho dinâmico, visando a interação, comunicação de equipes atuantes, também a permanente capacitação e aprendizado no interior das organizações, diferenciando as pessoas, valorizando o trabalho do grupo sem excluir o individual, transformando as empresas, criando novas estratégias e sendo um importante personagem no desenvolvimento organizacional (MACHADO, 2011, p.04).

Nessas perspectivas, Almeida (2006) destaca que, a atuação do pedagogo na empresa precisa acontecer de forma pertinente e cooperativa com a dos outros profissionais de gestão, assim, é possível organizar e estabilizar planos, projetos e ações visando à colaboração para a melhoria da atuação e desenvolvimento dos colaboradores, além de melhorar o desempenho da empresa.

\footnotetext{
Neste cenário que se apresenta, onde as empresas necessitam manter a competitividade no mercado, o investimento concretiza-se na valorização das competências dos colaboradores. Nesse campo a atuação do pedagogo empresarial é fundamental, colaborando não só nos processos de capacitação como também no diagnóstico e na avaliação constante das necessidades da organização (FERNANDES, 2004, p.253).
}

Desse modo, a intervenção do Pedagogo deve ser diretamente na área de recursos humanos, objetivando apaziguar os conflitos de relacionamento onde as pessoas possam trocar informações e estabelecer momentos de interação e descontração.

Nas palavras de Almeida (2006), entende-se que, o pedagogo mediante seu perfil e atuação na empresa, precisa entender e adentrar-se nesses instrumentos com o objetivo maior de colaborar dentro das organizações para construir melhores formas de utilizar os processos comunicacionais e de relações humanas na consolidação de práticas e políticas benéficas ao desenvolvimento humano e profissional.

Na visão de Fernandes (2004), o novo paradigma da sociedade do conhecimento é associar e expandir a rede de conhecimentos edificados nas empresas por meio da gestão do aprendizado organizacional. Logo, as organizações de sucesso devem impulsionar seus colaboradores à aprendizagem e valorização de seus conhecimentos, 
nas soluções dos problemas e na busca da inovação. Todavia, para o processo de aprendizagem organizacional deve-se contar com a presença do pedagogo empresarial, que por sua vez, pressupõe a participação de todos os integrantes, tendo em vista que, a característica marcante deste artifício é o desenvolvimento de habilidades e competências coletivas para obtenção de eficiência e eficácia dos resultados esperados.

\section{A IMPORTÂNCIA DA GESTÃO DE PESSOAS PARA O DESENVOLVIMENTO PROFISSIONAL}

Diante das concepções apresentadas a respeito do perfil e atuação do pedagogo, Duarte e Cabral (2010) afirma que, o pedagogo empresarial é o principal mediador na gestão de pessoas para o desenvolvimento profissional, com isso, seu papel é o de anunciar novos paradigmas, acrescentando subsídios que encaminhem todos os envolvidos a ampliar competências interpessoais. Esse processo é complexo e deve acontecer de maneira permanente na empresa em diversas situações.

Moscovici (2005) apud Duarte e Cabral (2010) salienta que, nesse processo de relacionamento humano dentro da empresa, é preciso cooperação, diálogo, respeito mútuo, laços de amizade para tornar o ambiente de trabalho harmônico e produtivo. Para isso, é preciso que o pedagogo empresarial desenvolva atitudes que auxiliem os colaboradores a tornarem suas relações sadias, aprendendo a conviver e a compartilhar saberes.

A partir dessas considerações, entende-se nas palavras de Duarte e Cabral (2010) que, cabe ao Pedagogo Empresarial oportunizar espaços de formação permanente para que ocorram significativas construções de aprendizagem pessoal e organizacional, com isso, há de se atingir um clima em prol do desenvolvimento profissional.

De acordo com Sampaio (2002, p.12), “as relações humanas e a gestão de pessoas deixam transparecer toda a sua importância ao tratar com as pessoas [...] em todos os lugares". E, para conviver bem no contexto empresarial é necessário respeitar a individualidade de cada pessoa.

Assim sendo, Duarte e Cabral (2010) enfatiza que, o Pedagogo na empresa tem a função de instigar ambientes que promovam a geração de relações dinâmicas para gerar 
o desenvolvimento integral das pessoas que compõem esse espaço, bem como para o alcance de resultados positivos na organização.

\footnotetext{
Os problemas de relacionamento se encontram, em sua maior parte, onde diferentes pessoas trabalham diariamente juntas. A boa comunicação e a utilização da cooperação são fatores essenciais para a realização das Relações Humanas de modo satisfatório. As expressões faciais ou corporais, as palavras e os gestos transmitem desejos, experiências, intenções e sentimentos (SAMPAIO, 2002, p.15).
}

Nessa perspectiva, Duarte e Cabral (2010) esclarece que, as empresas necessitam de profissionais e pedagogos empresariais que incentivem propostas de desenvolvimento humano e profissional, fomentando processos de aprendizagens contínuas.

Assim sendo, Sampaio (2002), dá destaque aos dez mandamentos das relações humanas no contexto empresarial:

a) Falar com as pessoas;

b) Sorrir para as pessoas;

c) Chamar as pessoas pelo nome;

d) Ser cordial;

e) Interessar-se sinceramente pelos outros;

f) Saber respeitar e valorizar os sentimentos dos outros;

g) Ser generoso ao elogiar, cauteloso ao criticar;

h) Ser amigo e prestativo;

i) Preocupar-se com a opinião dos outros: ouvir, aprender e elogiar;

j) Procurar apresentar um excelente serviço.

Diante disso, Marques (2012, p.47) complementa que, "a empresa deve dar suporte para o profissional desenvolver bem o seu papel [...]". Contudo, entende-se que, as relações humanas hoje é a peça primordial para alcançar resultados satisfatórios no contexto empresarial, tendo em vista que, o pedagogo empresarial deve se manter atento às experiências provenientes do conjunto de elementos indispensáveis da atividade laboral.

\section{METODOLOGIA}

Programas de Pós-Graduação em Ciências Sociais e Filosofia - UNIOESTE - Rua da Faculdade 645. Toledo - PR. CEP 85.903-000 Email: revistaalamedas@gmail.com 
Entende-se a metodologia como uma ciência que corresponde a um conjunto de métodos a ser utilizado na aquisição do conhecimento, todavia, é o estudo da melhor forma de tratar determinados problemas, em que não se procura soluções, mas seleciona maneiras de encontrá-las (BARROS, LEHFELD, 1994).

Na visão de Thiollent (1994), a metodologia orienta o pesquisador no processo de investigação, na tomada de decisões competentes, na seleção de conceitos, hipóteses, técnicas e informações adequadas.

Nesse sentido, a presente pesquisa foi bibliográfica com levantamento dos temas e tipos de abordagem já trabalhados por estudiosos, para assimilação de conceitos e exploração dos aspectos já publicados. Pois, segundo Barros e Lehfeld (1994), a pesquisa bibliográfica é efetuada para tentar resolver um problema e/ou adquirir conhecimentos a partir de informações advindas de materiais gráficos, sonoros e informatizados.

Assim sendo, foi de grande relevância a seleção de materiais catalogados em bibliotecas e internet, tais como livros e artigos científicos. A partir daí, foi efetuada uma coleta de dados e informações para aquisição de conhecimentos sobre o tema "O Pedagogo Empresarial como Mediador da Gestão de Pessoas para o Desenvolvimento Profissional", e com isso, realizou-se leitura crítica e reflexiva para contextualizar e desenvolver o trabalho.

Na concepção de Gil (2002), esta pesquisa também foi exploratória, a qual teve como finalidade, oferecer maior familiaridade com o problema, tornando-o mais explícito, uma vez que, envolveu levantamento bibliográfico. E, Richardson (1999, p.66) complementa que, "a pesquisa exploratória é utilizada quando não se tem informação sobre determinado tema e se deseja conhecer o fenômeno".

Nessas perspectivas, foi possível compreender a problemática sobre o perfil e atuação do pedagogo como mediador da gestão de pessoas no contexto empresarial, tendo em vista que, atualmente, o mercado de trabalho exige profissionais qualificados e capacitados a atuar com objetividade e humanização, considerando a complexidade existente no contexto do relacionamento humano.

\section{CONSIDERAÇÕES FINAIS}

Programas de Pós-Graduação em Ciências Sociais e Filosofia - UNIOESTE - Rua da 
Considerando toda a abordagem exposta neste trabalho, foi possível compreender que, a Pedagogia é um campo do conhecimento de extrema importância, pois, é a partir dela que se promovem habilidades e competências necessárias ao profissional Pedagogo. Por isso, ela é considerada Ciência e Arte da Educação, porque investiga, concentram, analisa, executa e determina o objetivo da educação por meio da observação e experimentação. Além disso, a Pedagogia faz conexão de forma perspicaz e dinâmica à empresa.

Entretanto, teve-se clareza de que, Pedagogia e Empresa formam uma parceria necessária, pois ambas buscam o mesmo objetivo, isto é, provocar mudanças no comportamento das pessoas, e o mundo moderno impõem cada vez mais exigências. Mediante estas implicações, entende-se que, o grande desafio para as empresas é incluir em seu contexto o profissional Pedagogo Empresarial, o qual irá dar apoio para o entendimento dessas questões. A partir daí, foi possível entender que, este profissional pode ser considerado o intercessor de novos caminhos e paradigmas dentro da empresa para transformar, modificar e elevar o ser humano em sua totalidade.

Nessas perspectivas, compreendeu-se que, o perfil do Pedagogo Empresarial é o de perceber, observar, envolver, desprender, ter coragem, conhecimento e empatia, pois o significado inicial do trabalho do pedagogo na empresa está no valor que lhe é atribuído pela própria organização.

Todavia, o perfil e a atuação do Pedagogo Empresarial são pontos decisivos para que este profissional desenvolva seu trabalho com valor e qualidade na empresa.

Por tudo isso, foi possível concluir que, o Pedagogo Empresarial é o principal mediador na Gestão de Pessoas no contexto corporativo, e esta é uma tarefa complexa, a qual compreende a totalidade do ser em sua conexão com o mundo, o que exige relações dinâmicas e sadias. Dessa maneira, as empresas necessitam deste profissional para incentivar propostas de desenvolvimento humano, provocando processos de aprendizagens contínuas.

\section{BIBLIOGRAFIA}

ALMEIDA, M. G. de. Pedagogia empresarial: saberes, práticas e referências. São Paulo: Brasport, 2006. 
BARROS, A. J. da S.; LEHFELD, N. A. de S. Fundamentos de metodologia científica. 3. ed. São Paulo: Pearson Prentice Hall, 2007.

DUARTE, A. N.; CABRAL, S. M. Pedagogia empresarial: concepções e desafios. In: FRANCISCO, D. A.; SCHNEIDER, E. C. (Org.). Ações, reflexões e desafios na formação do pedagogo na contemporaneidade. Novo Hamburgo: Feevale, p, 91 $100,2010$.

FERNANDES, M. Pedagogia empresarial: o conhecimento pedagógico na organização - espaço de quem? In: ZORZO, M. C.; SILVA, L. D; POLENZ, T. (Org.). Pedagogia em Conexão. Canoas: ULBRA, p. 252 - 259, 2004.

GHIRALDELLI JÚNIOR, P. O que é pedagogia. São Paulo: Brasiliense, 2006.

GIL, A. C. Como elaborar projetos de pesquisa. 4. ed. São Paulo: Atlas, 2002.

HOLTZ, M. L. M. Lições de pedagogia empresarial. (2006). MH Assessoria Empresarial Ltda., Sorocaba - $\quad$ SP. Disponível em: <http://www.mh.etc.br/documentos/licoes_de_pedagogia_empresarial.pdf>. Acesso em: 01 ago. 2015.

MACHADO, L. A. R. de L. Pedagogia empresarial: histórico e perspectivas atuais. In: XV ENCONTRO LATINO AMERICANO DE INICIAÇÃO CIENTÍFICA E XI ENCONTRO LATINO AMERICANO DE PÓS-GRADUAÇÃO - UNIVERSIDADE DO VALE DO PARAÍBA. Anais. Paraíba: UNIVAP, p, 01 - 05, 2011.

MARQUES, W. L. Persuadir: o curso. Cianorte: Clube dos autores, 2012.

PAZ, C. P. da; CARVAlHO, T. N. O RH e a pedagogia empresarial. (2010). Disponível em: <http://www.pedagogia.com.br/artigos/rhpedagogiaempresarial/index.php?pagina=0> Acesso em: 01 ago. 2015.

RICHARDSON, R. J. Pesquisa social: métodos e técnicas. São Paulo: Atlas, 1999.

SAMPAIO, G. P. As relações humanas a toda hora. São Paulo: Nobel, 2000. As relações humanas de cada dia. São Paulo: Nobel, 2002.

THIOLLENT, M. Metodologia da pesquisa-ação. 6. ed. São Paulo: Cortez, 1994. http://www.portaleducacao.com.br/administracao/artigos/17860/a-bibliografia-nagestao-de-pessoas. Acesso em: 01 ago. 2015.

LUIZARI, K. R. Comunicação Empresarial Eficaz: como falar e escrever bem. Curitiba: IBPEX, 2010. 
Revista eletrônica de

Ciências Sociais e Filosofia

MACHADO, R. M. Ética e relacionamento interpessoal. Senac: São Paulo, 2002. 